\title{
VERY LATE BIORESORBABLE VASCULAR SCAFFOLD THROMBOSIS AT 25 MONTHS POST IMPLANTATION
}

Singapore Med J 2017; 58(9): 571-572 doi: 10.11622/smedj.2017089

Dear Sir,

Bioresorbable vascular scaffolds (BRS) have been heralded as the fourth revolution in interventional cardiology following coronary angioplasty, bare-metal stents and drug-eluting stents. ${ }^{(1)}$ One of the most desirable features of BRS is their temporary presence in the vessel wall. Clinical and experimental data have shown that at three years after implantation, BRS struts were completely resorbed and replaced by connective tissue, allowing the restoration of a functional endothelium. ${ }^{(2)}$ This potentially reduces the risk of late (one month to one year after implantation) or very late (more than one year after implantation) scaffold thrombosis. However, the case we herein report showed that very late scaffold thrombosis (VLScT) can still occur with BRS when the bioresorption process is advanced or nearly complete.

A 52-year-old man underwent percutaneous coronary intervention of a chronic total occlusion in his proximal left anterior descending artery with two overlapping BRS ( $2.5 \mathrm{~mm} \times 28 \mathrm{~mm}$ and $3 \mathrm{~mm} \times 28 \mathrm{~mm}$ Absorb BVS, Abbott Vascular, Santa Clara, CA, USA). He was on dual antiplatelet therapy for one year and aspirin alone thereafter. At 25 months post implantation, he presented with non-ST-segment elevation myocardial infarction without acute electrocardiography changes, which had started while he was cycling. Coronary angiography showed thrombotic occlusion in the distal scaffold (Fig. 1a). Following aspiration thrombectomy (Fig. 1b), optical coherence tomography (OCT) revealed intraluminal thrombus (Figs. 2a \& b); residual scaffold 'black boxes', which were strut footprints filled in with connective tissue (Figs. 2b \& c); and a thin neointimal layer along the entire length of the two wellexpanded BRS, including their overlapping sites (Figs. 1b \& 2c). The 'black boxes' should not be discernible by OCT at five years following full integration into the vessel wall. ${ }^{(3)}$ After balloon angioplasty of the distal scaffold with a proprietary $2.75 \mathrm{~mm} \times 15 \mathrm{~mm}$ noncompliant balloon and adjunctive intravenous eptifibatide infusion, final angiography (Fig. 1c) showed thrombus resolution and normal antegrade vessel flow. OCT revealed well-apposed scaffold struts after balloon angioplasty.

Early and midterm BRS thromboses have been well documented ${ }^{(4)}$ and are typically due to suboptimal scaffold deployment associated with bulky scaffold struts, which in themselves may delay endothelialisation or give rise to abnormal rheological conditions
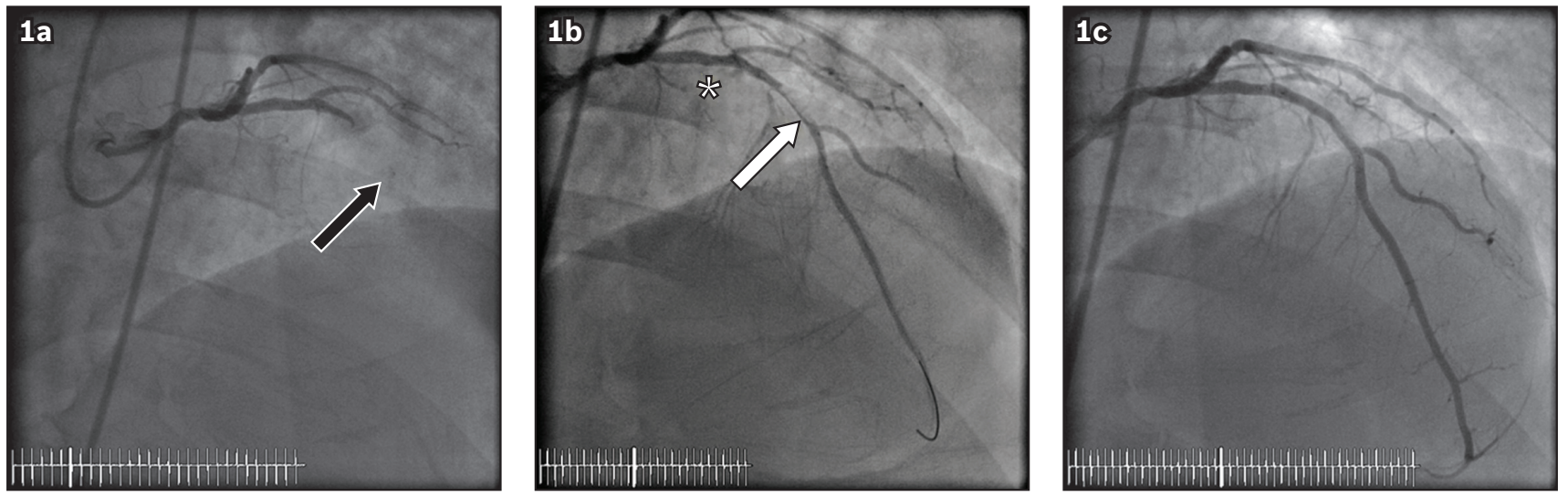

Fig. 1 Coronary angiograms show (a) thrombotic occlusion in the distal scaffold (black arrow), (b) angiographic filling defect due to residual thrombus following thrombectomy (white arrow) and a thin neointimal layer along the entire length of the two well-expanded bioresorbable vasscular scaffolds, including their overlapping sites $\left({ }^{*}\right)$, and (c) thrombus resolution and normal antegrade vessel flow after balloon angioplasty of the distal scaffold.
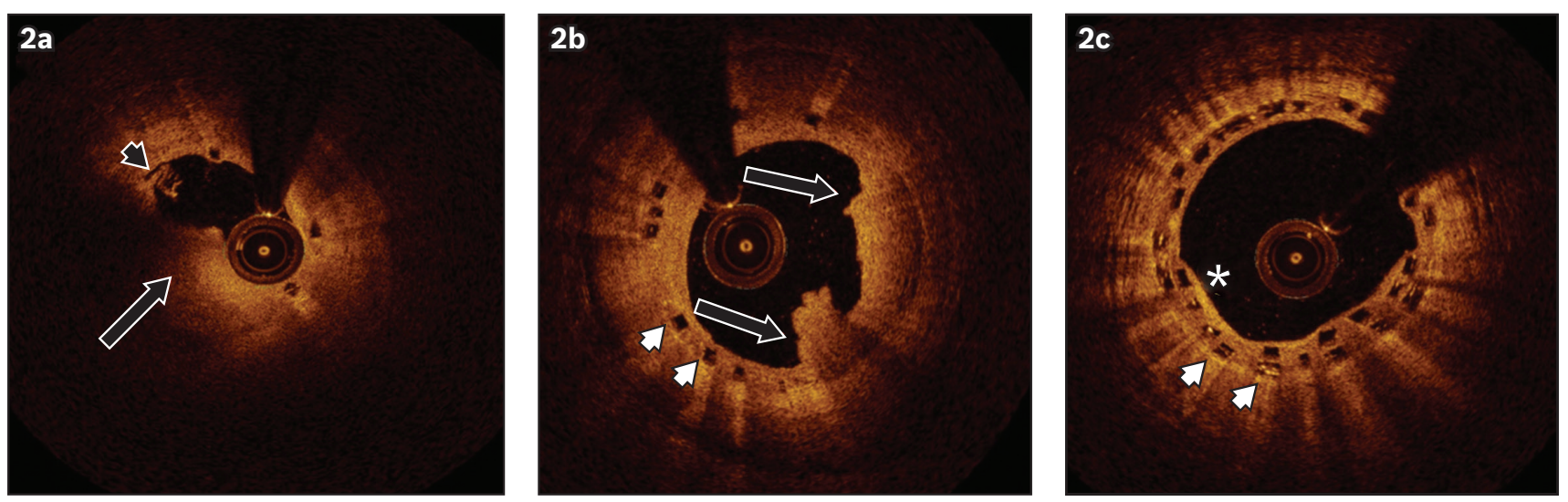

Fig. 2 Optical coherence tomography images show (a) intraluminal thrombus (black arrow) and a malapposed scaffold strut in the thrombotic segment (black arrowhead); (b) intraluminal thrombus (black arrow) and residual scaffold 'black boxes', which are strut footprints filled in with connective tissue (white arrowheads in b \& c); and (c) residual scaffold 'black boxes' and a thin neointimal layer along the entire length of the two well-expanded bioresorbable vasscular scaffolds, including their overlapping sites $\left({ }^{*}\right)$. 
favouring coagulation activation. The phenomenon of VLScT is, however, rarely reported. To our knowledge, only a dozen cases have been described worldwide in small case series ${ }^{(5,6)}$ and individual case reports. ${ }^{(7-11)}$ Putative mechanisms of VLScT include total discontinuation of antiplatelet therapy, ${ }^{(8)}$ late scaffold recoil, ${ }^{(10)}$ and other mechanical factors inducing abnormal flow, such as scaffold underexpansion, malapposed or uncovered (unendothelialised) scaffold struts, ${ }^{(5)}$ and late scaffold discontinuity (due to the resorption process) causing the dislocation of strut remnants into the vessel lumen. ${ }^{(6,11)}$

In our case, the underlying thrombotic substrate could not be clearly identified due to the significant amount of residual thrombus post thrombectomy and before balloon angioplasty. However, there was a malapposed scaffold strut in the thrombotic segment (Fig. 2a), and we postulated that the thrombotic process was likely triggered by scaffold malapposition. As there was no baseline intracoronary imaging study during the index procedure, it was not possible to determine if the scaffold malapposition was persistent following deployment, or acquired late (due to scaffold resorption). Had the scaffold malapposition been persistent, this case would highlight the need for a truly optimal post-deployment result, as the resorption of the scaffold itself may not protect it from very late thrombosis.

In conclusion, thrombosis of BRS may still occur even in the late stages of the scaffold resorption process. More research is required to refine the physical properties of BRS, confirm whether cases of VLSCT are truly rare, elucidate the mechanisms responsible and ascertain the optimal duration of dual antiplatelet therapy to reduce such adverse events.

Yours sincerely,

Koo Hui $\underline{\mathrm{Chan}}^{1}$, Swee-Chong $\underline{\mathrm{Seow}}^{1}$, Huay Cheem $\underline{\operatorname{Tan}}^{1}$

${ }^{1}$ Cardiac Department, National University Heart Centre, Singapore. koo_chan@hotmail.com

\section{REFERENCES}

1. Iqbal J, Onuma Y, Ormiston J, et al. Bioresorbable scaffolds: rationale, current status, challenges, and future. Eur Heart J 2014; 35:765-76.

2. Serruys PW, Onuma Y, Garcia-Garcia HM, et al. Dynamics of vessel wall changes following the implantation of the absorb everolimus-eluting bioresorbable vascular scaffold: a multi-imaging modality study at 6, 12, 24 and 36 months. Eurolntervention 2014; 9:1271-84.

3. Karanasos A, Simsek C, Gnanadesigan M, et al. OCT assessment of the long-term vascular healing response 5 years after everolimus-eluting bioresorbable vascular scaffold. J Am Coll Cardiol 2014; 64:2343-56.

4. Capodanno D, Gori T, Nef H, et al. Percutaneous coronary intervention with everolimus-eluting bioresorbable vascular scaffold in routine clinical practice: early and midterm outcomes from the European multicentre GHOST-EU registry. Eurolntervention 2015; 10:1144-53.

5. Karanasos A, Van Mieghem N, van Ditzhuijzen N, et al. Angiographic and optical coherence tomography insights into bioresorbable scaffold thrombosis: single-center experience. Circ Cardiovasc Interv 2015; 8:e002369.

6. Raber L, Brugaletta S, Yamajik K, et al. Very late scaffold thrombosis: intracoronary imaging and histopathological and spectroscopic findings. J Am Coll Cardiol 2015; 66:1901-14.

7. Sato T, Abdel-Wahad M, Richardt G. Very late thrombosis observed on optical coherence tomography 22 months after the implantation of a polymer-based bioresorbable vascular scaffold. Eur Heart J 2015; 36:1273.

8. Timmers L, Stella PR, Agostoni P. Very late bioresorbable vascular scaffold thrombosis following discontinuation of antiplatelet therapy. Eur Heart J 2015 ; 36:393.

9. Azzalini L, Al-Hawwas M, L'Allier P. Very late bioresorbable vascular scaffold thrombosis: a new clinical entity. Eurolntervention 2015; 11:e1-2.

10. Cortese B, Piraino D, lelasi A, Steffenino G, Orrego PS. Very late bioresorbable vascular scaffold thrombosis due to late device recoil. Int J Cardiol 2015; 189:132-3.

11. Ielasi A, Cortese B, Steffenino G. Late structural discontinuity as a possible cause of very late everolimus-eluting bioresorbable scaffold thrombosis. JACC Cardiovasc Interv 2015; 8:e171-2. 